\title{
The New Elderly Patient: A Necessary Upgrade
}

\author{
Santo Catapano ${ }^{1, *(\mathbb{D}}$, Luca Ortensi ${ }^{2}$, Nicola Mobilio ${ }^{1}$ and Francesco Grande ${ }^{1, *(D)}$ \\ 1 Department of Prosthodontics, University of Ferrara, Via Luigi Borsari 46, 44121 Ferrara, Italy; \\ mblncl@unife.it \\ 2 Department of Prosthodontics, University of Catania, 95123 Catania, Italy; luca@ortensistrocchi.it \\ * Correspondence: cts@unife.it (S.C.); francesco.grande90@gmail.com (F.G.); Tel.: +39-0532688501 (S.C. \& F.G.)
}

check for updates

Citation: Catapano, S.; Ortensi, L.; Mobilio, N.; Grande, F. The New Elderly Patient: A Necessary

Upgrade. Prosthesis 2021, 3, 99-104. https://doi.org/10.3390/ prosthesis 3010010

Received: 5 February 2021

Accepted: 12 March 2021

Published: 15 March 2021

Publisher's Note: MDPI stays neutral with regard to jurisdictional claims in published maps and institutional affiliations.

Copyright: (c) 2021 by the authors. Licensee MDPI, Basel, Switzerland. This article is an open access article distributed under the terms and conditions of the Creative Commons Attribution (CC BY) license (https:// creativecommons.org/licenses/by/ $4.0 /)$.

\begin{abstract}
The elderly individual is becoming the most common patient in clinical practice due to the increasing average life span, especially in developed countries. The current elderly patients are different from those of some decades ago. They usually have an active social life, want to be informed, and are actively involved in the current society with consequent high expectations for medical and dental treatment. However, not all the elderly patients are like this. Some of them show limited financial resources, reduced mental and manual skills, and poor motivation. The purpose of this communication is to make a brief characterization of the new elderly population in view of prosthetic and dental management.
\end{abstract}

Keywords: elderly patient; prosthetic rehabilitation; dental treatment; population characteristics

\section{Introduction}

The challenge of the modern medicine is to promote the prolongation of life in good health, while reducing morbidity and disabilities [1]. In this context, oral health is fully involved; it is well established that good oral health correlates with healthy aging and with reduced morbidity and mortality $[2,3]$.

Aging, which is, in part, a determinant of the lifespan of a human, can be defined simplistically as the continuing loss of physiological integrity and subsequent impaired function leading to death [4]. Generally, the elderly population is considered to include those over 65 years old [5]. However, in recent decades, the reduction in fertility and the increase of average life span, especially in industrialized developed countries, has made this segment of the population much more represented in the society [6]. Therefore, population over 65 years old has been divided into two parts: those between 65 and 75 years old and those over 75 years old.

However, age is not a useful criterion in dentistry to divide the elderly population because of the extreme heterogeneity of this group [7]. In fact, it is possible to find people of similar age who are completely healthy or with one or more morbidities, subjects with various degrees of frailty (biological or economic frailty), different degrees of education, and different economic resources. In the dental field, it is possible to recognize completely toothed subjects with good oral health, partially edentulous patients with various degrees of soft and hard tissue decay, and fully edentulous subjects. Then, dental clinicians have to treat subjects with many different needs [8], from those who only need prevention and maintenance to patients with more or less complex dental pathological conditions that interact with systemic morbidities and/or pathologies.

Despite the fact that oral aging is a current focus of several organizations, actually we are far from the goal set by the Japanese Association, which is for each person to retain more than 20 teeth by age 80 [9].

Therefore, it is fundamental to know the characteristics of the currently elderly population in order to correctly assess the dental needs of the patients in relation to the physiological processes of aging occurring in the stomatognathic apparatus and related to 
local or systemic pathologies. The purpose of this work is to make a brief characterization of the new elderly population in view of prosthetic and dental management.

\section{The Elderly Patient}

Aging is a physiological process that involves the alteration of the intraoral homeostatic balance, because of the changes in the oral microbiota and the reduction of the salivary glands' production [10]. This can lead to an alteration of the oral mucosa, with the appearance of intra-oral pain syndromes [11] and decreased oral motor functions [12]. There is an increase in the prevalence of periodontitis and caries [3,13]. The pathogenetic moments recognize both direct factors, such as the loss of immunity and cellular aging, and indirect factors such as physical and cognitive decay [14]. All this occurs above all in the non-self-sufficient elderly and those with cognitive problems; the final outcome of periodontal disease and caries is the loss of teeth which, in turn, triggers a whole series of anatomical-functional alterations in the stomatognathic system $[3,13]$. Impaired masticatory function, linked to tooth loss, as well as myo-articular functional and taste alterations, can lead elderly subjects to eliminate some foods from their diet with important nutritional consequences [15]. The lower intake of fruit and vegetables and the increased consumption of foods rich in fatty acids and carbohydrates expose partially and fully edentulous patients to high risk of obesity [16], cardiovascular disease [17], hypertension [18], type 2 diabetes [19], and other pathologies [20].

It is fundamental to assess the degree of oral frailty of each patient, intended as a condition, not a disease, that manifests with specific signs or symptoms such as decreased articulation, slight choking or spillage while eating, and an increased number of unchewable foods. The process by which older people become dependent is generally gradual but could be fast, and the state of oral health, dental treatment, and prevention also changes according to the stage [21]. Minakuchi et al. [22] tried to classify the degree of oral frailty into four stages (healthy state, oral frailty, oral hypofunction, and oral dysfunction) establishing diagnostic criteria and management strategies to reduce the risk of oral hypofunction among older people. They start from the concept that sarcopenia and malnutrition are closely involved in the cycle of frailty, which contains many psychological factors and social factors [23]. The study group of the National Center for Geriatrics and Gerontology in Japan also shows that recovery can be expected by various interventions before succumbing frailty [24]. In this way, it is important not only to maintain oral hygiene for preventing periodontitis and dental caries but also to restore oral function by placing an appropriate prosthesis for tooth loss [25-29]. Consequently, there is a growing awareness that the recovery and maintenance of oral function help delay the onset of conditions requiring nursing care, thereby helping to extend healthy life expectancy.

Therapy planning and treatment goals must be determined by taking into account the individual's capacity. Dental treatment for someone with impaired cognitive function may be perceived as violation and invasion of personal integrity [30]. Realistic goals of what can be achieved need to be established. A complicating factor is that in recent years, tooth loss has increasingly been treated with implant-based prosthesis and the incidence of peri-implantitis has also increased. For the frail elderly, this may lead to the need for advanced dental care, which can be impossible for them to cope with.

In order to manage these patients, it is crucial to know the general health status of the patient and the possible influence of systemic pathologies and drugs (e.g., bisphosphonate assumption) on the health of the oral cavity. All the systemic factors could critically affect not only the treatment execution but also the prognosis of the oral treatments. It is also important to know when older adults enter the frail state that would result in the process of losing independence. 


\section{Characteristic of the Elderly Patient}

The decision-making process for the oral management of elderly patients is then conditioned by the extreme heterogeneity of the general conditions, which can be different from the healthy subject to the subject with varying degrees of frailty and disability (Figure 1).

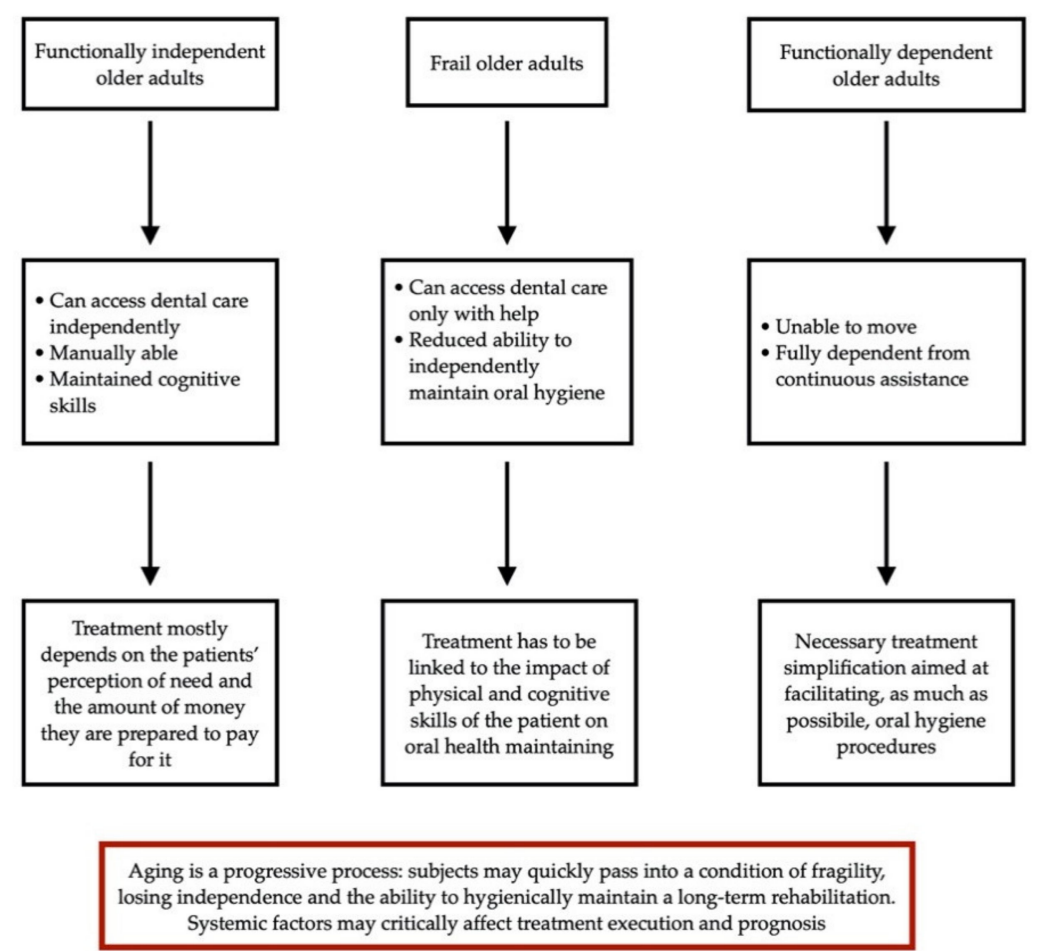

Figure 1. Flow chart of decision-making for older adults starting from Ettinger and Beck classification.

According to the degree of conservation of functional skills and the ability to seek dental services, Ettinger and Beck [31] proposed a classification of elderly subjects into three groups: functionally independent older adults, frail older adults, and functionally dependent older adults.

Functional independent older adults represent about $70 \%$ of the population over 65 years old [5]. These people may present some systemic problems (such as hypertension, type II diabetes, etc.) but they can access dental care independently, are manually able, and their treatment will depend mostly on the patients' perception of need and the amount of money they are prepared to pay for it. However, regardless of the treatment plan, it is fundamental to consider that aging is a progressive process and that these subjects may quickly pass into a condition of fragility, losing independence and the ability to hygienically maintain a long-term rehabilitation.

Frail older adults and functionally dependent older adults are comprised in the group of patients who are no longer able to take care of their own health independently and need ongoing assistance.

Frail older adults are people who no longer access general dental services without the help of others. Their oral health needs require a greater understanding of medicine and pharmacology and a careful evaluation of their ability to maintain daily oral hygiene independently, as well as their ability to tolerate treatment. They represent about $20 \%$ of elderly subjects and still live in the community with the help of family and friends or use professional support services. In this case, the necessary evaluation has to be linked to the ability of the patient or professional care supporter to maintain his/her oral health over time evaluating then difficulties in hygiene procedures on prosthetic devices. There is a risk that health and medical professionals and staff in home care do not give adequate priority to oral health and mouth care, due to, e.g., lack of time or lack of knowledge [32]. 
An ethical problem may arise when the older person with maintained physical skills but with cognitive impairment refuses to accept oral hygiene procedures as part of routine daily care. Nursing staff may perceive a conflict between respect for the patient's autonomy and providing good and safe care.

Patients of the third group, defined as functionally dependent older adults, are subjects unable to move and fully dependent on continuous assistance. They live either at home (about $5 \%$ of the population over 65 ) or in institutions (another $5 \%$ of the population over 65). Taking care of these subjects, who are no longer able to independently maintain their oral health and/or go to a dental clinic, usually means to perform dental interventions at the patient's home and especially, to instruct the assistance staff in maintaining a correct hygiene of the residual teeth, oral mucosa, and prosthesis. It is necessary to simplify both conservative and prosthetic treatments in order to make the interventions as effective as possible for maintaining the patient's oral health. It is also interesting to highlight that some systematic reviews showed that effective oral hygiene can prevent pneumonia [33] and nutritional factors also relate to oral health [34], pointing out the importance of oral health in relation to systemic health in these patients. Furthermore, tentative evidence indicates an independent association between oral health status and malnutrition in the elderly residing in a long-term care facility [34]. A new dental challenge would be the development of person-centered care for these frail elderly patients, in collaboration with nursing personnel providing daily support through home care and in nursing homes.

\section{Conclusions}

The decision-making process for the oral health management in elderly patients is conditioned by the extreme heterogeneity of the general health and oral conditions of the patients, which can be different from the healthy subject to the subject with varying degrees of frailty and disability. Different approaches could be possible based on the conditions mentioned above. A patient-centered evaluation, according to the degree of conservation of physical and cognitive skills, is important for the treatment planning and management of elderly patients in order to recover or maintain the oral functions, delaying the onset of conditions requiring nursing care, thereby helping to extend healthy life expectancy. However, when treating elderly patients, it is necessary that clinicians keep in mind that aging is a progressive process, and healthy subjects could quickly pass into a condition of fragility, losing independence and the ability to hygienically maintain a long-term rehabilitation. Furthermore, systemic factors may critically affect not only the treatment execution but also the prognosis of the oral treatments.

Author Contributions: Conceptualization, S.C. and F.G.; writing-original draft preparation, F.G.; writing-review and editing, N.M. and F.G.; supervision, L.O.; project administration, S.C. All authors have read and agreed to the published version of the manuscript.

Funding: This research received no external funding.

Institutional Review Board Statement: Not applicable.

Informed Consent Statement: Not applicable.

Data Availability Statement: Not applicable.

Conflicts of Interest: The authors declare no conflict of interest.

\section{References}

1. Hashim, M.J. The Art of Healing-Core Values and Goals of Medicine, Nursing and Healthcare. J. Coll. Physicians Surg. Pak. 2019, 29, 299-300. [CrossRef]

2. Kanasi, E.; Ayilavarapu, S.; Jones, J. The aging population: Demographics and the biology of aging. Periodontology 2016, $72,13-18$. [CrossRef] [PubMed]

3. Romandini, M.; Baima, G.; Antonoglou, G.; Bueno, J.; Figuero, E.; Sanz, M. Periodontitis, Edentulism, and Risk of Mortality: A Systematic Review with Meta-analyses. J. Dent. Res. 2021, 100, 37-49. [CrossRef]

4. López-Otín, C.; Blasco, M.A.; Partridge, L.; Serrano, M.; Kroemer, G. The hallmarks of aging. Cell 2013, 15, 1194-1217. [CrossRef] 
5. Ettinger, R.L. Treatment planning concepts for the ageing patient. Aust. Dent. J. 2015, 60, 71-85. [CrossRef] [PubMed]

6. Newgard, C.B.; Sharpless, N.E. Coming of age: Molecular drivers of aging and therapeutic opportunities. J. Clin. Investig. 2013, 123, 946-950. [CrossRef]

7. Ettinger, R.L. Cohort differences among aging populations: A challenge for the dental profession. Spec. Care Dentist. 1993, 13, 19-26. [CrossRef]

8. D'Amico, C.; Bocchieri, S.; Sambataro, S.; Surace, G.; Stumpo, C.; Fiorillo, L. Occlusal Load Considerations in Implant-Supported Fixed Restorations. Prosthesis 2020, 2, 23. [CrossRef]

9. Müller, F.; Naharro, M.; Carlsson, G.E. What are the prevalence and incidence of tooth loss in the adult and elderly population in Europe? Clin. Oral Implants Res. 2007, 18, 2-14. [CrossRef]

10. Johansson, A.-K.; Johansson, A.; Unell, L.; Ekbäck, G.; Ordell, S.; Carlsson, G.E. Self-reported dry mouth in Swedish population samples aged 50, 65 and 75 years. Gerodontology 2012, 29, e107-e115. [CrossRef]

11. Gibson, S.J.; Lussier, D. Prevalence and relevance of pain in older persons. Pain Med. 2012, 13, S23-S26. [CrossRef] [PubMed]

12. Ástvaldsdóttir, Á.; Boström, A.; Davidson, T.; Gabre, P.; Gahnberg, L.; Sandborgh Englund, G.; Skott, P.; Ståhlnacke, K.; Tranæus, S.; Wilhelmsson, H.; et al. Oral health and dental care of older persons-A systematic map of systematic reviews. Gerodontology 2018, 35, 290-304. [CrossRef]

13. Papapanou, P.N.; Sanz, M.; Buduneli, N.; Dietrich, T.; Feres, M.; Fine, D.H.; Flemmig, T.F.; Garcia, R.; Giannobile, W.V.; Graziani, F.; et al. Periodontitis: Consensus report of workgroup 2 of the 2017 World Workshop on the Classification of Periodontal and Peri-Implant Diseases and Conditions. J. Clin. Periodontol. 2018, 45, S162-S170. [CrossRef]

14. Gilbert, P. The evolved basis and adaptive functions of cognitive distortions. Br. J. Med. Psychol. 1998, 71, 447-463. [CrossRef]

15. Wilson, I.B.; Cleary, P.D. Linking clinical variables with health-related quality of life. A conceptual model of patient outcomes. JAMA 1995, 273, 59-65. [CrossRef] [PubMed]

16. Österberg, T.; Dey, D.K.; Sundh, V.; Carlsson, G.E.; Jansson, J.-O.; Mellström, D. Edentulism associated with obesity: A study of four national surveys of 16416 Swedes aged 55-84 years. Acta Odontol. Scand. 2010, 68, 360-367. [CrossRef]

17. Holmlund, A.; Holm, G.; Lind, L. Number of teeth as a predictor of cardiovascular mortality in a cohort of 7674 subjects followed for 12 years. J. Periodontol. 2010, 81, 870-876. [CrossRef]

18. Gordon, J.H.; LaMonte, M.J.; Zhao, J.; Genco, R.J.; Cimato, T.R.; Hovey, K.M.; Allison, M.A.; Mouton, C.P.; Wactawski-Wende, J. Association of Periodontal Disease and Edentulism With Hypertension Risk in Postmenopausal Women. Am. J. Hypertens. 2019, 32, 193-201. [CrossRef]

19. Taboza, Z.A.; Costa, K.L.; Silveira, V.R.; Furlaneto, F.A.; Montenegro, R.; Russell, S.; Dasanayake, A.; Rego, R.O. Periodontitis, edentulism and glycemic control in patients with type 2 diabetes: A cross-sectional study. BMJ Open Diabetes Res. Care. 2018, 6, e000453. [CrossRef]

20. Sierpinska, T.; Golebiewska, M.; Dlugosz, J.; Kemona, A.; Laszewicz, W. Connection between masticatory efficiency and pathomorphologic changes in gastric mucosa. Quintessence Int. 2007, 38, 31-37.

21. Cicciù, Cervino, Terranova, Risitano, Raffaele, Cucinotta. Prosthetic and Mechanical Parameters of the Facial Bone under the Load of Different Dental Implant Shapes: A Parametric Study. Prosthesis 2019, 1, 6. [CrossRef]

22. Minakuchi, S.; Tsuga, K.; Ikebe, K.; Ueda, T.; Tamura, F.; Nagao, K.; Furuya, J.; Matsuo, K.; Yamamoto, K.; Kanazawa, M. Oral hypofunction in the older population: Position paper of the Japanese Society of Gerodontology in 2016. Gerodontology 2018, 35, 317-324. [CrossRef]

23. Xue, Q.-L.; Bandeen-Roche, K.; Varadhan, R.; Zhou, J.; Fried, L.P. Initial manifestations of frailty criteria and the development of frailty phenotype in the Women's Health and Aging Study II. J. Gerontol. A Biol. Sci. Med. Sci. 2008, 63, 984-990. [CrossRef]

24. Shinsho, F. New strategy for better geriatric oral health in Japan: 80/20 movement and Healthy Japan 21. Int. Dent. J. 2001, 51, 200-206. [CrossRef]

25. Ortensi, L.; Ortensi, M.; Minghelli, A.; Grande, F. Implant-Supported Prosthetic Therapy of an Edentulous Patient: Clinical and Technical Aspects. Prosthesis 2020, 2, 13. [CrossRef]

26. Tallarico, M.; Cervino, G.; Scrascia, R.; Uccioli, U.; Lumbau, A.; Meloni, S.M. Minimally Invasive Treatment of Edentulous Maxillae with Overdenture Fully Supported by a Cad/Cam Titanium Bar with a Low-Profile Attachment Screwed on Four or Six Implants: A Case Series. Prosthesis 2020, 2, 6. [CrossRef]

27. Montanari, M.; Scrascia, R.; Cervino, G.; Pasi, M.; Ferrari, E.; Xhanari, E.; Koshovari, A.; Tallarico, M. A One-Year, Multicenter, Retrospective Evaluation of Narrow and Low-Profile Abutments Used to Rehabilitate Complete Edentulous Lower Arches: The OT Bridge Concept. Prosthesis 2020, 2, 33. [CrossRef]

28. Scrascia, R.; Fiorillo, L.; Gaita, V.; Secondo, L.; Nicita, F.; Cervino, G. Implant-Supported Prosthesis for Edentulous Patient Rehabilitation. From Temporary Prosthesis to Definitive with a New Protocol: A Single Case Report. Prosthesis 2020, $2,2$. [CrossRef]

29. Ceraulo, S.; Leonida, A.; Lauritano, D.; Baldoni, A.; Longoni, S.; Baldoni, M.; Caccianiga, G. Proposal for a Clinical Approach to Geriatric Patients with Anchor Need on Implant for Removable Denture: New Technique. Prosthesis 2020, 2, 16. [CrossRef]

30. Nordenram, G.; Norberg, A.; Bischofberger, E. Ethical aspects of dental care for demented patients. Methodological considerations. Swed. Dent. J. 1994, 18, 155-164. [PubMed]

31. Ettinger, R.L.; Beck, J.D. Geriatric dental curriculum and the needs of the elderly. Spec. Care Dentist. 1984, 4, 207-213. [CrossRef] [PubMed] 
32. Wårdh, I.; Jonsson, M.; Wikström, M. Attitudes to and knowledge about oral health care among nursing home personnel—An area in need of improvement. Gerodontology 2012, 29, e787-e792. [CrossRef] [PubMed]

33. Sjögren, P.; Nilsson, E.; Forsell, M.; Johansson, O.; Hoogstraate, J. A systematic review of the preventive effect of oral hygiene on pneumonia and respiratory tract infection in elderly people in hospitals and nursing homes: Effect estimates and methodological quality of randomized controlled trials. J. Am. Geriatr. Soc. 2008, 56, 2124-2130. [CrossRef] [PubMed]

34. Van Lancker, A.; Verhaeghe, S.; Van Hecke, A.; Vanderwee, K.; Goossens, J.; Beeckman, D. The association between malnutrition and oral health status in elderly in long-term care facilities: A systematic review. Int. J. Nurs. Stud. 2012, 49, 1568-1581. [CrossRef] 